\title{
Craniopharyngiomas : Radiological Differentiation of Two Types
}

\author{
In Ho Lee, M.D., ${ }^{1,2}$ Elcin Zan, M.D., ${ }^{1}$ W. Robert Bell, M.D., ${ }^{3}$ Peter C. Burger, M.D., ${ }^{3}$ Heejong Sung, Ph.D., ${ }^{4}$ David M. Yousem, M.D., M.B.A. ${ }^{1}$ \\ The Russell H. Morgan Department of Radiology and Radiological Sciences, ${ }^{1}$ Department of Pathology, ${ }^{3}$ The Johns Hopkins Medical Institutions, \\ Baltimore, MD, USA \\ Department of Radiology, ${ }^{2}$ Chungnam National University Hospital, Chungnam National University School of Medicine, Daejeon, Korea \\ Genometrics Section, ${ }^{4}$ Computational and Statistical Genomics Branch, National Human Genome Research Institute, National Institutes of Health, \\ Baltimore, MD, USA
}

Objective : To determine imaging features that may separate adamantinomatous and papillary variants of craniopharyngiomas given that tumors with adamantinomatous signature features are associated with higher recurrence rates, morbidity, and mortality. We specifically reviewed calcification on CT, T1 bright signal intensity, and cystic change on T2 weighted images for differentiating these two types.

Methods : We retrospectively reviewed the MRI and CT studies in 38 consecutive patients with pathologically proven craniopharyngiomas between January 2004 and February 2014 for the presence of calcification on CT scans, bright signal intensity on T1 weighted images, and cystic change on T2 weighted images.

Results : Of the 38 craniopharyngiomas, 30 were adamantinomatous type and 8 were papillary type. On CT scans, calcification was present in 25 of 38 tumors. All calcified tumors were adamantinomatous type. Twenty four of 38 tumors had bright signal intensity on T1 weighted images. Of these 24 tumors, 22 (91.7\%) were adamantinomatous and 2 were papillary type. Cystic change on T2 weighted images was noted in 37 of 38 tumors; only 1 tumor with papillary type did not show cystic change.

Conclusion : T1 bright signal intensity and calcification on CT scans uniformly favor the adamantinomatous type over papillary type of craniopharyngioma in children. However, these findings are more variable in adults where calcification and $\mathrm{T} 1$ bright signal intensity occur in $70.6 \%$ and $58.8 \%$ respectively of adult adamantinomatous types of craniopharyngiomas.

Key Words : Craniopharyngioma - Tomography scanners, X-ray computed · Magnetic resonance imaging.

\section{INTRODUCTION}

Craniopharyngiomas are common suprasellar and/or intrasellar tumors, account for $3 \%$ of all intracranial tumors, and are divided into adamantinomatous and papillary types ${ }^{16)}$. It is useful to radiologically differentiate adamantinomatous type from papillary type because prognoses differ. Age, calcification, cyst formation or MR signal intensity may be helpful for the differential diagnosis of the two types ${ }^{20)}$.

Although a previous study reported that calcification on CT and intratumoral $\mathrm{T} 1$ bright signal intensity were more frequent in adamantinomatous type than papillary type ${ }^{20)}$, there are only a few articles attempting to differentiate them ${ }^{8,20)}$.

The imaging features may also play a role in the differential diagnosis of suprasellar tumors (T1 bright in dermoids, lipomas, teratomas due to fat content; thrombosed aneurysms due to blood products; and calcification in meningiomas, aneurysms, teratomas) $)^{24,29)}$.

The purpose of this report is to evaluate the calcification on CT scans, T1 bright signal intensity, and cystic change on T2 weighted images for differentiating adamantinomatous type from papillary type craniopharyngiomas. We also wished to verify the differential prognosis between two types of craniopharyngiomas.

\section{MATERIALS AND METHODS}

This retrospective study was reviewed and approved by our Institutional Review Board. Due to the retrospective nature of the study, informed patient consent was not required for the re-

- Received : January 13, 2016 • Revised : June 4, 2016 •Accepted : July 4, 2016

- Address for reprints : In Ho Lee, M.D.

Department of Radiology, Chungnam National University Hospital, Chungnam National University School of Medicine, 282 Munhwa-ro, Jung-gu, Daejeon 35015, Korea

Tel : +82-42-280-8065, Fax : +82-42-253-0061, E-mail : leeinh01974@hanmail.net

- This is an Open Access article distributed under the terms of the Creative Commons Attribution Non-Commercial License (http://creativecommons.org/licenses/by-nc/3.0) which permits unrestricted non-commercial use, distribution, and reproduction in any medium, provided the original work is properly cited. 
view of medical records and radiographic exams. The study was HIPAA compliant.

We retrospectively reviewed the imaging findings and medical records of 38 consecutive patients with pathologically proven craniopharyngiomas (26 men, 12 women; age range, 3 months ${ }^{-}$ 74 years, mean age, $37.6 \pm 24.4$ years) between January 2004 and February 2014.

We evaluated the presence of calcification on CT scans, presence of $\mathrm{T} 1$ bright signal intensity and presence of cystic change on T2 weighted images.

Two neuro-radiologists (8 years of experiences, 3 years of experiences) independently assessed the MRI and CT studies. If there was a discrepancy between two observers, adjudication between the two reviewers was performed by a third neuro-radiologist (25 years of experiences).

The MRI studies consisted of a standard protocol of sagittal and coronal T1 weighted, axial T2 weighted, FLAIR images and axial, sagittal and coronal T1 weighted images after contrast administration. All sections were $5 \mathrm{~mm}$ or thinner.

The CT scans consisted of axial pre-contrast CT and postcontrast CT images. All sections were $5 \mathrm{~mm}$ or thinner.

In 6 of 38 patients with recurrent tumors, pre-operative MRI or CT studies were not available. However, follow up brain MRI and CT studies before subsequent reoperation were available in these 6 patients.

Pre-contrast CT scans were not available in 6 patients. In these patients, we used the post-contrast CT scans with bone algorithm and bone windows to evaluate for calcification.

When there was any high signal intensity within the mass on T1 weighted image, regardless of extent or location, we classified the mass as positive for T1 bright signal intensity. When there was non-enhancing high signal intensity on T2 weighted image, regardless of extent or location, we classified the mass as positive for cystic change on $\mathrm{T} 2$ weighted image.

We compared the incidence of calcification on CT scans, T1 bright signal intensity, and cystic change on T2 weighted images between two groupings (adamantinomatous type and papillary type, pediatric patients and adult patients). We also evaluated the extent of operation, incidence of recurrence, and mortality in all patients.

Pediatric patients were defined as less than or equal to 18 years of age and adult patients was defined as more than 18 years of age.

We used two sided Fisher's exact test using R by hypothesizing the independence between two groups. We rejected the hypothesis at the significance level of 0.05 by having a $p$-value $<0.05$. We also measured the sensitivity, specificity, positive predictive value, negative predictive value, and accuracy.

\section{RESULTS}

The 38 patients presented with various complaints including visual problems, headaches, memory problems, hormonal deficiencies, macrocephaly, or neck pain. Among them, visual problems or headaches were most common (30/38 patients, $79 \%$ ).

Of the 38 craniopharyngiomas, 30 were adamantinomatous type and 8 were papillary type. The ages for the adamantinomatous and papillary type showed means and standard deviations of $31.9 \pm 23.9$ years and $58.8 \pm 12.3$ years, respectively (significantly different, $p<0.05)$. All pediatric patients had an adamantinomatous type of craniopharyngioma $(13 / 13,100 \%)$ while adult patients showed a mixture of adamantinomatous type $(17 / 25,68 \%)$ and papillary type $(8 / 25,32 \%)$.

On CT scans, calcification was noted in 25 tumors $(25 / 38$, $65.8 \%), 25 / 30$ (83.3\%) with adamantinomatous type and $0 / 8$ with papillary type (significantly different, $p<0.05$ ). Calcification was more common in pediatric patients $(13 / 13,100 \%)$ than adult patients $(12 / 25,48 \%)$ (significantly different, $p<0.05$ ) (Table 1,2 , 3, Fig. 1, 2, 3).

On brain MRI, there was T1 bright signal intensity in 24 tu-

Table 1. The relationship between calcification on CT and the two types of craniopharyngiomas

\begin{tabular}{lccl}
\hline & Adamantinomatous type & Papillary type & \\
\hline Calcification $(+)$ & 25 & 0 & Positive predictive value $(25 / 25,100 \%)$ \\
Calcification $(-)$ & 5 & 8 & Negative predictive value $(8 / 13,61.5 \%)$ \\
& Sensitivity $(25 / 30,83.3 \%)$ & Specificity $(8 / 8,100 \%)$ & Accuracy $(33 / 38,86.8 \%)$ \\
\hline
\end{tabular}

Table 2. The incidence of calcification on $\mathrm{CT}, \mathrm{T} 1$ bright signal intensity, and cystic change on $\mathrm{T} 2$ weighted images according to age

\begin{tabular}{lccr}
\hline & Pediatric patients (less than or equal to 18 years) & Adult patients (more than 18 years) & Fisher's exact test \\
\hline Calcification (+) & $13 / 13(100 \%)$ & $12 / 25(48 \%)$ & $p<0.05$ \\
T1 bright signal intensity $(+)$ & $12 / 13(92.3 \%)$ & $12 / 25(48 \%)$ & $p<0.05$ \\
Cystic change (+) & $13 / 13(100 \%)$ & $24 / 25(96 \%)$ & $p>0.05$ \\
\hline
\end{tabular}

Table 3. The incidence of calcification on CT, T1 bright signal intensity, and cystic change on $\mathrm{T} 2$ weighted images according to two types

\begin{tabular}{|c|c|c|c|}
\hline & Adamantinomatous type & Papillary type & Fisher's exact test \\
\hline Calcification $(+)$ & $25 / 30(83.3 \%)$ & $0 / 8(0 \%)$ & $p<0.05$ \\
\hline T1 bright signal intensity $(+)$ & $22 / 30(73.3 \%)$ & $2 / 8(25 \%)$ & $p<0.05$ \\
\hline Cystic change (+) & $30 / 30(100 \%)$ & $7 / 8(87.5 \%)$ & $p>0.05$ \\
\hline
\end{tabular}


mors (24/38, 63.2\%); these included 22/30 (73.3\%) adamantinomatous type and $2 / 8$ (25\%) papillary type (significantly different, $p<0.05)$. Twenty two of 24 tumors (91.7\%) that were bright on T1-weighted images were adamantinomatous type. T1 bright
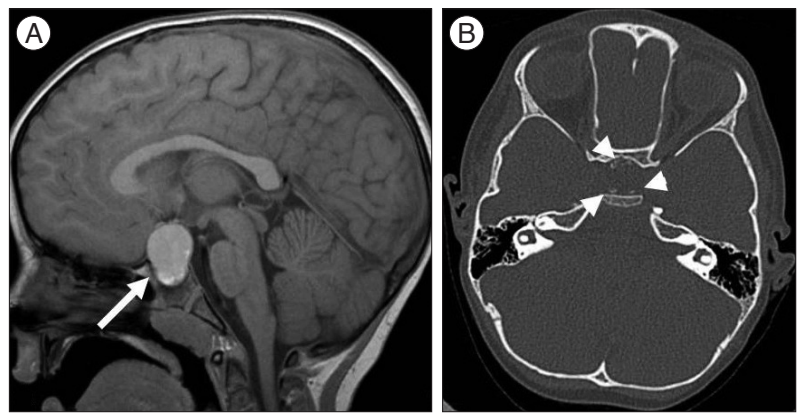

Fig. 1. 2-year old boy with craniopharyngioma (adamantinomatous type). A : Sagittal T1 weighted image shows diffuse bright signal intensity (arrow) in the sellar and suprasellar mass. B : Non-contrast axial CT scan shows curvilinear high density (arrowheads) in the peripheral portion of mass, indicating calcification.
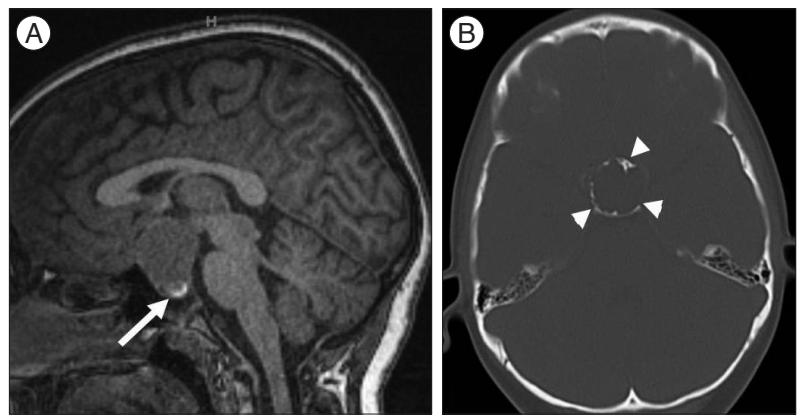

Fig. 2. 10-year old boy with craniopharyngioma (adamantinomatous type). A : Sagittal T1 weighted image shows bright signal intensity (arrow) in the lower portion of sellar and suprasellar mass. B : Non-contrast axial CT scan shows curvilinear high density (arrowheads) in the peripheral portion of mass, indicating calcification.
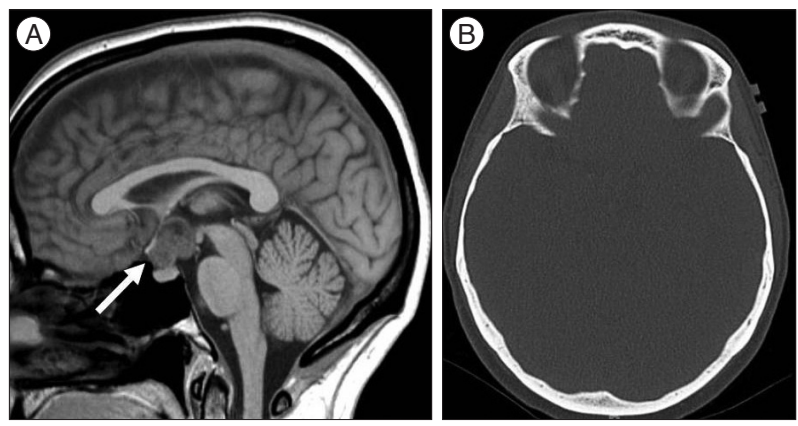

Fig. 3. 54-year old woman with craniopharyngioma (papillary type). A : Sagittal T1 weighted image shows no bright signal intensity (arrow) in the sellar and suprasellar mass. B : Non-contrast axial CT scan shows no high density in the mass, indicating calcification. signal intensity was more common in pediatric patients $(12 / 13$, $92.3 \%)$ than adult patients $(12 / 25,48 \%)$ (significantly different, $p<0.05$ ) (Table 2, 3, 4, Fig. 1, 2, 3).

Of 30 adamantinomatous tumors, pediatric patients showed uniform imaging features of calcification on CT $(13 / 13,100 \%)$ and $\mathrm{T} 1$ bright signal intensity $(12 / 13,92.3 \%)$ while adult patients showed more variable features of calcification on CT $(12 / 17$, $70.6 \%)$ and $\mathrm{T} 1$ bright signal intensity $(10 / 17,58.8 \%)$ even when just looking at adamantinomatous varieties.

Cystic change on $\mathrm{T} 2$ weighted images was noted in 37 of 38 tumors (97.4\%) with only 1 tumor, a papillary type, that did not show any cystic change. There was no significant difference in cystic change on $\mathrm{T} 2$ weighted images between pediatric patients $(13 / 13,100 \%)$ and adult patients $(24 / 25,96 \%)$ (Table 2, 3).

Tumor recurrence was noted in 18 patients $(18 / 30,60 \%)$ with adamantinomatous type and 4 patients $(4 / 8,50 \%)$ with papillary type (not significantly different, $p>0.05$ ). Of $22 / 38$ patients with recurrence, there were $18 / 21$ patients with limited resection (adamantinomatous type : $15 / 18$ patients, papillary type : $3 / 3$ patients) and 4/17 patients with gross total resection (adamantinomatous type : $3 / 12$ patients, papillary type : $1 / 5$ patient). However, we were not able to obtain the information about the degree of initial resection in 2 patients with adamantinomatous type, who underwent initial operation at an outside hospital and then gross total resection at our hospital.

Gross total resection was performed in 17 patients and additional radiotherapy was performed in $2 / 17$ patients while limited resection including cyst aspiration was performed in 21 patients and additional radiotherapy was performed in 11/21 patients.

No perioperative deaths within 1 month after surgery, nor deaths within the follow-up period of 3 months -9 years 10 months were detected. However, 3 patients were lost to follow up.

\section{DISCUSSION}

Craniopharyngiomas are intracranial epithelial neoplasms arising from remnants of the craniopharyngeal duct or Rathke's pouch $^{19)}$. These tumors occur in children as well as adults, with bimodal age distribution with peak incidences at 5 to 14 , and 50 to 74 years ${ }^{3)}$.

Craniopharyngiomas are histologically benign, World Health Organization grade I neoplasms, but these tumors are considered clinically aggressive due to their tendency to recur. It is difficult to resect these lesions completely because of their adherence to adjacent vital structures including the vessels, optic pathway, hypothalamus, and pituitary stalk ${ }^{14,26,28)}$. Additionally, inflammation associated with the tumors may cause a diffi-

Table 4. The relationship between $\mathrm{T} 1$ bright signal intensity and the two types of craniopharyngiomas

\begin{tabular}{lccc}
\hline & Adamantinomatous type & Papillary type & \\
\hline T1 bright signal intensity $(+)$ & 22 & 2 & Positive predictive value $(22 / 24,91.7 \%)$ \\
T1 bright signal intensity (-) & 8 & 6 & Negative predictive value $(6 / 14,42.9 \%)$ \\
& Sensitivity $(22 / 30,73.3 \%)$ & Specificity $(6 / 8,75 \%)$ & Accuracy $(28 / 38,73.7 \%)$ \\
\hline
\end{tabular}


cult gross total resection due to tumor adhesion and infiltration to adjacent to brain ${ }^{18)}$. Tumor invasion to adjacent brain tissue is more frequently demonstrated in the adamantinomatous type $e^{11)}$.

Previous studies reported that age, tumor size, location of the tumor, composition of the tumor, presence of calcification, initial symptoms of intracranial hypertension, grade of hydrocephalus, extent and type of surgery, and histological type can affect the recurrence or morbidity rate $e^{1,6,9-11,13,21)}$. However, the validity of these findings is still being debated in the literature ${ }^{12,13,17)}$. Some studies have reported that the papillary type had a more favorable prognosis than adamantinomatous type ${ }^{1,22,23)}$ while others reported that there was no significant difference between them ${ }^{4,7,15,25)}$.

Given the potential differential prognosis, it is important to differentiate adamantinomatous type from papillary type in preoperative diagnosis. There are some radiological clues that may distinguish between the two types such as calcification and T1 bright signal intensity. We specifically evaluated the calcification on CT scans, T1 bright signal intensity, and cystic change on T2 weighted images.

Calcification is a common finding in craniopharyngiomas with incidences from $65.3 \%$ to $74.8 \%{ }^{16,28)}$. Calcification is more common in children (90\%) than in adult (70\%) and in the adamantinomatous type than papillary type $e^{5,20,27)}$. Our study revealed that calcification was much more common in pediatric patients (100\%) than adult patients (48\%) and adamantinomatous type (83.3\%) than papillary type (0\%). However, we also point out, which was not previously described, that there is a difference in the calcification rate in adamantinomatous type between children $(13 / 13,100 \%)$ and adult patients $(12 / 17,70.6 \%)$.

The T1 bright signal intensity of craniopharyngiomas could be secondary to high protein content, cholesterol, mild calcification or hemorrhage $\mathrm{e}^{2,5)}$. In our study, the papillary type showed T1 bright signal intensity in only $25 \%(2 / 8)$ while most of adamantinomatous type $(73.3 \%, 22 / 30)$ showed $\mathrm{T} 1$ bright signal intensity regardless of amount and location. Once again we found an age difference. The pediatric adamantinomatous varieties were bright on T1 weighted images in 12/13 (92.3\%) but in only 10/17 (58.8\%) adult adamantinomatous varieties. Even though our prevalence of $\mathrm{T} 1$ bright signal intensity and calcification on CT scans in the various types of craniopharyngiomas was similar to those reported in previous studies ${ }^{13,16,20)}$, this age differential is a new facet of the description.

Cystic change on T2 weighed images was a common finding in both adamantinomatous type (100\%) and papillary type $(87.5 \%)$ as well as both pediatric patients (100\%) and adult patients $(96 \%)$. In contrast to T1 bright signal intensity and calcification on CT scans, cystic change on T2 weighted images was not helpful for the differential diagnosis between two types.

In our study, there were no significant differences in recurrence rate and mortality rate between adamantinomatous type and papillary type. Therefore, we cannot verify the differential prognosis between two types.

There are several limitations in this study. First, although there were significant differences between two types, the sample size of this study was small. Second, all patients had MRI and CT studies, but 6 of them did not have initial pre-operative MRI or CT studies (but did have follow-up studies before surgery) and 6 of them did not have pre-contrast CT scans relying on bone algorithm and bone windows to detect calcification. This made evaluation of fine calcification versus contrast enhancement more difficult.

\section{CONCLUSION}

T1 bright signal intensity and calcification on CT scans and pediatric age range favor the adamantinomatous type over papillary type of craniopharyngiomas. In adults, the signal intensity and presence of calcification are more variable because the histological type is less uniformly adamantinomatous. Additionally while pediatric adamantinomatous tumors are uniformly calcified (100\%) and bright on T1 weighted images (92.3\%), the adult adamantinomatous tumors calcify in $70.6 \%$ and are $\mathrm{T} 1$ bright in $58.8 \%$.

Although we did not find the differences in prognosis between two types, tumors with adamantinomatous features have been shown in previous literature to be associated with higher recurrence rates, morbidity, and mortality. Preoperative prediction of diagnosis based on imaging features may help to facilitate therapeutic decision making.

\section{References}

1. Adamson TE, Wiestler OD, Kleihues P, Yaşargil MG : Correlation of clinical and pathological features in surgically treated craniopharyngiomas. J Neurosurg 73 : 12-17, 1990

2. Ahmadi J, Destian S, Apuzzo ML, Segall HD, Zee CS : Cystic fluid in craniopharyngiomas : MR imaging and quantitative analysis. Radiology 182: 783-785, 1992

3. Bunin GR, Surawicz TS, Witman PA, Preston-Martin S, Davis F, Bruner JM : The descriptive epidemiology of craniopharyngioma. J Neurosurg 89 : 547-551, 1998

4. Crotty TB, Scheithauer BW, Young WF Jr, Davis DH, Shaw EG, Miller GM, et al. : Papillary craniopharyngioma : a clinicopathological study of 48 cases. J Neurosurg $83: 206-214,1995$

5. Curran JG, O'Connor E : Imaging of craniopharyngioma. Childs Nerv Syst $21: 635-639,2005$

6. De Vile CJ, Grant DB, Kendall BE, Neville BG, Stanhope R, Watkins KE : Management of childhood craniopharyngioma : can the morbidity of radical surgery be predicted? J Neurosurg 85 : 73-81, 1996

7. Duff J, Meyer FB, Ilstrup DM, Laws ER Jr, Schleck CD, Scheithauer BW : Long-term outcomes for surgically resected craniopharyngiomas. Neurosurgery $46: 291-302,2000$

8. Eldevik OP, Blaivas M, Gabrielsen TO, Hald JK, Chandler WF : Craniopharyngioma : radiologic and histologic findings and recurrence. AJNR Am J Neuroradiol 17 : 1427-2439, 1996

9. Fisher PG, Jenab J, Gopldthwaite PT, Tihan T, Wharam MD, Foer DR : Outcomes and failure patterns in childhood craniopharyngiomas. Childs Nerv Syst 14 : 558-563, 1998

10. Gautier A, Godbout A, Grosheny C, Tejedor I, Coudert M, Courtillot C, et al. : Markers of recurrence and long-term morbidity in craniopharyngioma : a systematic analysis of 171 patients. J Clin Endocrinol Metab 
$97: 1258-1267,2012$

11. Gupta DK, Ojha BK, Sarkar C, Mahapatra AK, Mehta VS : Recurrence in craniopharyngiomas : analysis of clinical and histological features. J Clin Neurosci $13: 438-442,2006$

12. Jo KW, Shin HJ, Kong DS, Seol HJ, Nam DH, Lee JI : Treatment outcomes of pediatric craniopharyngioma : a 15-year retrospective review of 35 cases. J Korean Neurosurg Soc 52 : 37-41, 2012

13. Kim SK, Wang KC, Shin SH, Choe G, Chi JG, Cho BK : Radical excision of pediatric craniopharyngioma : recurrence pattern and prognostic factors. Childs Nerv Syst $17: 531-536,2001$

14. Komotar RJ, Roguski M, Bruce JN : Surgical management of craniopharyngiomas. J Neurooncol $92:$ 283-296, 2009

15. Miller DC : Pathology of craniopharyngiomas : clinical import of pathological findings. Pediatr Neurosurg 21 suppl 1 : 11-17, 1994

16. Mollá E, Martí-Bonmatí L, Revert A, Arana E, Menor F, Dosdá R, et al. : Craniopharyngiomas : identification of different semiological patterns with MRI. Eur Radiol 12 : 1829-1836, 2002

17. Pekmezci M, Louie J, Gupta N, Bloomer MM, Tihan T : Clinicopathological characteristics of adamantinomatous and papillary craniopharyngiomas : University of California, San Francisco experience 19852005. Neurosurgery $67: 1341-1349,2010$

18. Petito CK : Craniopharyngioma : prognostic importance of histologic features. AJNR Am J Neuroradiol 17 : 1441-1442, 1996

19. Prabhu VC, Brown HG : The pathogenesis of craniopharyngiomas. Childs Nerv Syst $21: 622-627,2005$

20. Sartoretti-Schefer S, Wichmann W, Aguzzi A, Valavanis A : MR differentiation of adamantinous and squamous-papillary craniopharyngiomas. AJNR Am J Neuroradiol 18 : 77-87, 1997
21. Shapiro K, Till K, Grant DN : Craniopharyngiomas in childhood. A rational approach to treatment. J Neurosurg $50: 617-623,1979$

22. Szeifert GT, Sipos L, Horváth M, Sarker MH, Major O, Salomváry B, et al. : Pathological characteristics of surgically removed craniopharyngiomas : analysis of 131 cases. Acta Neurochir (Wien) 124:139-143, 1993

23. Tavangar SM, Larijani B, Mahta A, Hosseini SM, Mehrazine M, Bandarian F : Craniopharyngioma : a clinicopathological study of 141 cases. Endocr Pathol 15 : 339-344, 2004

24. Warakaulle DR, Anslow P : Differential diagnosis of intracranial lesions with high signal on T1 or low signal on T2-weighted MRI. Clin Radiol 58 : 922-933, 2003

25. Weiner HL, Wisoff JH, Rosenberg ME, Kupersmith MJ, Cohen H, Zagzag D : Craniopharyngiomas : a clinicopathological analysis of factors predictive of recurrence and functional outcome. Neurosurgery 35 : 1001-1010, 1994

26. Zacharia BE, Bruce SS, Goldstein H, Malone HR, Neugut AI, Bruce JN : Incidence, treatment and survival of patients with craniopharyngioma in the surveillance, epidemiology and end results program. Neuro Oncol 14 : 1070-1078, 2012

27. Zhang YQ, Wang CC, Ma ZY : Pediatric craniopharyngiomas : clinicomorphological study of 189 cases. Pediatr Neurosurg 36 : 80-84, 2002

28. Zhao X, Yi X, Wang H, Zhao H : An analysis of related factors of surgical results for patients with craniopharyngiomas. Clin Neurol Neurosurg 114 : 149-155, 2012

29. Zimny A, Zińska L, Bladowska J, Neska-Matuszewska M, Sąsiadek M : Intracranial lesions with high signal intensity on T1-weighted MR images - review of pathologies. Pol J Radiol 78 : 36-46, 2013 